\title{
Visual and Refractive Outcomes Following Simultaneous Phacoemulsification and Pterygium Excision with Conjunctival Autograft
}

\author{
Shreesha Kumar Kodavoor ${ }^{1}$, Soundarya $B^{1}$, Ramamurthy Dandapani ${ }^{2}$ \\ ${ }^{1}$ Cornea Services, the Eye foundation, Coimbatore, India \\ ${ }^{2}$ Cataract and Refractive Services, the Eye Foundation, Coimbatore, India
}

Email address:

Email id-eskay_03@rediffmail.com (Shreesha K. K.), soundslikeme@gmail.com (Soundarya B), drramamurthy@theeyefoundation.com (Ramamurthy D.)

\section{To cite this article:}

Shreesha Kumar Kodavoor, Soundarya B, Ramamurthy Dandapani. Visual and Refractive Outcomes Following Simultaneous Phacoemulsification and Pterygium Excision with Conjunctival Autograft. International Journal of Ophthalmology \& Visual Science. Vol. 4, No. 4, 2019, pp. 106-110. doi: 10.11648/j.ijovs.20190404.19

Received: November 19, 2019; Accepted: December 16, 2019; Published: December 24, 2019

\begin{abstract}
Purpose - This study aims at analyzing the visual and refractive outcomes following simultaneous phacoemulsification and pterygium excision with conjunctival autograft (CAG). Setting-Tertiary eye care hospital in South India. Design-Retrospective study. Methods-508 eyes that underwent simultaneous phacoemulsification with pterygium excision between 2011-2017 were included in the study. Exclusion criteria-Pre-operative astigmatism of $>2 \mathrm{D}$, grade 3 pterygia, recurrent or double head pterygia, traumatic or complicated cataract. Pre-operative evaluation-clinical examination, keratometry, IOL power calculation, retinoscopy and subjective refraction. Procedure-Phacoemulsification with foldable monofocal IOL followed by pterygium excision with conjunctival autografting using tissue glue. Post-operative follow upPeriodically up to 6 months. Results- Mean pre-operative best corrected visual acuity (LogMAR) was $0.41+/-0.46$ with postoperative mean being $0.04+/-0.12(\mathrm{p}=0.001)$. Mean pre-operative and post operative astigmatism were $-1.25+/-0.60 \mathrm{D}$ and $0.73+/-0.58 \mathrm{D}(\mathrm{p}=0.001)$ respectively. Mean post-operative myopic spherical error was $-0.85+/-0.48 \mathrm{D} .34 .33 \%$ of the patients had a post-operative refractive error out of which $87.42 \%$ had myopia and $12.57 \%$ had a hypermetropic error (<1D). $63.27 \%$ of the eyes with myopic error had an error of $<1 \mathrm{D}$. Most commonly seen complication was sub conjunctival haemorrhage followed by graft retraction in 12 and 10 eyes respectively. Conclusion- The combined single step procedure of phacoemulsification with pterygium excision in indicated cases, is safe and effective with good visual outcomes. The postoperative myopic residual error can be anticipated and reduced by slightly under correcting the IOL power in patients with concurrent pterygium to optimize the visual outcome.
\end{abstract}

Keywords: Phacoemulsification, Pterygium, Conjunctival Autograft

\section{Introduction}

Pterygium, a wing shaped fibrovascular connective tissue extension of the bulbar conjunctiva into the corneal surface, is one of the more prevalent ocular surface disorders which occurs more commonly in older age groups, especially in those with excessive UV exposure [1, 2]. A higher prevalence of pterygia is seen to exist in an equatorial belt between latitudes 37 degrees north and 37 degrees south [3]. The relationship between UV exposure and cataract formation has also been extensively studied $[4,5]$, thus making UV exposure a common etiological factor for both pterygium and cataract, the simultaneous occurrence of which is not uncommon, especially in tropical countries like India. Pterygia usually have only cosmetic implications, but in some cases may cause changes in refraction due to localized corneal flattening leading to astigmatism and increasing corneal aberrations and can lead to visual symptoms due to invasion into the visual axis. The induced astigmatism depends on the length, width and depth of the pterygium extending into the cornea [6].

The simultaneous presence of cataract and pterygium [7], 
especially in the older age group, raises the question of when to perform the pterygium excision with respect to the cataract surgery. A 2 step surgery of pterygium excision later followed by cataract surgery with IOL implantation may avoid the above problems, but a simultaneous procedure is usually preferred by the patients as it results in rapid visual improvement and better cosmetic outcomes with an additional benefit of lesser number of hospital visits, patient convenience and lower cost of surgery $[8,9]$. This study aims at analyzing the visual and refractive outcomes following simultaneous phacoemulsification and pterygium excision with conjunctival autograft $(\mathrm{CAG})$.

\section{Methods}

508 eyes of 508 patients who underwent combined phacoemulsification and pterygium excision between the period of 2011 and 2017 were retrospectively studied. Institutional Review Board approval was obtained and patients' consent had been obtained for the procedure. All patients underwent a pre operative evaluation that included routine keratometry, retinoscopy and subjective refraction, IOL power calculation with IOL Master using Hoffer Q formula for eyes with short axial length, Holladay II for normal axial lengths and SRK-T for longer axial lengths.

\subsection{Inclusion Criteria}

The pterygia were graded according to the extent of involvement (Grade 1: crossing limbus; Grade 2: midway between limbus and pupil; Grade 3: reaching up to pupillary margin; and Grade 4: crossing pupillary margin) [10]. Patients with significant cataract and grade 1 or grade 2 pterygium with an astigmatism of less than $2 \mathrm{D}$ and with a minimum post operative follow up of 6 months were included in the study.

\subsection{Exclusion Criteria}

Pre operative astigmatism values were used as a criteria to exclude patients with values more than $2 \mathrm{D}$. Patients with grade 3 pterygia, any grade of recurrent pterygia and double head pterygia, traumatic cataract, complicated cataract and associated corneal or retinal pathology were excluded from the study.

\subsection{Procedure}

All patients underwent phacoemulsification with foldable monofocal IOL implantation under topical or peribulbar anaesthesia. All surgeries were done through a temporal clear corneal $2.8 \mathrm{~mm}$ incision except for cases with temporal pterygium where a superior clear corneal incision was used. This was followed by excision of pterygium with conjunctival autograft taken from the superior conjunctiva and the graft was fixed using tissue glue-Tisseel (Baxter, Vienna, Austria) in all cases.

\subsection{Post Operative Follow $U$ p}

Patients were started post operatively on topical antibiotics (0.5\% Moxifloxacin) 4 times a day for 2 weeks, topical steroids $(0.5 \%$ Loteprednol) for 4 weeks and preservative free tear substitutes $(0.5 \%$ Carboxy methyl cellulose) for 6 weeks. Post operative evaluation was done on POD 1,2 weeks, 6 weeks and 6 months, which included clinical examination and refraction.

\subsection{Statistical Analysis}

Statistical analysis was done with the SPSS (statistical package for social sciences) software using the t-test. Statistical significance was defined as $\mathrm{p}<0.05$.

\section{Results}

The mean age of the patients studied was $62.76+/-7.29$ years. 212 patients $(41.74 \%)$ were between $40-60$ years, 284 patients $(55.90 \%)$ were between the age group of $61-80$ years and 12 patients $(2.36 \%)$ were above the age of 80 years. Out of the 508 patients $312(61.42 \%)$ were males and 196 (38.58\%) were females. 190 (37.41\%) had grade 1 pterygia and $318(62.59 \%)$ had grade 2 pterygia.

As seen in Table 1, a significant improvement in visual acuity was seen post operatively. The mean pre operative best corrected visual acuity (LogMAR) was $0.41+/-0.46$ which improved to a mean of $0.04+/-0.12$ post operatively, which was found to be statistically significant $(\mathrm{p}<0.05)$.

Table 2 and Figure 1 compare the pre operative and post operative astigmatism in the patients, with a division into 3 groups-nil cylindrical error, less than $1 \mathrm{D}$ and 1.25 to $2 \mathrm{D}$. A shift from higher to lower cylindrical error was seen in the patients which can be seen as a redistribution of cases among the 3 groups. The mean pre operative astigmatism was found to be $-1.25+/-0.60 \mathrm{D}$ which reduced to a post operative mean of $-0.73+/-0.58 \mathrm{D}$, which was found to be statistically significant $(\mathrm{p}<0.05)$.

Table 1. Pre operative and Post operative BCVA.

\begin{tabular}{lll}
\hline $\begin{array}{l}\text { BCVA range } \\
\text { (LogMAR) }\end{array}$ & $\begin{array}{l}\text { PRE OPERATIVE } \\
\text { (Number-\%) }\end{array}$ & $\begin{array}{l}\text { POST OPERATIVE } \\
\text { (Number-\%) }\end{array}$ \\
\hline $6 / 6-6 / 12(0-0.3)$ & $302(59.44)$ & $498(98.03)$ \\
$6 / 18-6 / 60(0.5-1)$ & $140(27.55)$ & $10(1.96)$ \\
$<6 / 60(>1)$ & $66(12.99)$ & $0(0)$ \\
Mean LogMAR & $0.41+/-0.46$ & $0.04+/-0.12(\mathrm{p}=0.001)$ \\
\hline
\end{tabular}

Table 2. Pre operative and post operative manifest astigmatism.

\begin{tabular}{lll}
\hline $\begin{array}{l}\text { Astigmatism } \\
\text { range }\end{array}$ & $\begin{array}{l}\text { PRE OPERATIVE } \\
\text { Number (\%) }\end{array}$ & $\begin{array}{l}\text { POST OPERATIVE } \\
\text { Number }(\%)\end{array}$ \\
\hline 0 & $48(9.45)$ & $160(31.49)$ \\
$<=1 \mathrm{D}$ & $212(41.74)$ & $246(48.43)$ \\
$1.25-2 \mathrm{D}$ & $248(48.81)$ & $98(19.29)$ \\
NA & $0(0.0)$ & $4(0.79)$ \\
Total & $508(100)$ & $508(100)$ \\
Mean cylindrical & $-1.25+/-0.60 \mathrm{D}$ & $-0.73+/-0.58 \mathrm{D}(\mathrm{p}=0.001)$ \\
\hline
\end{tabular}

BCVA-Best Corrected Visual Acuity, NA-Not Available 


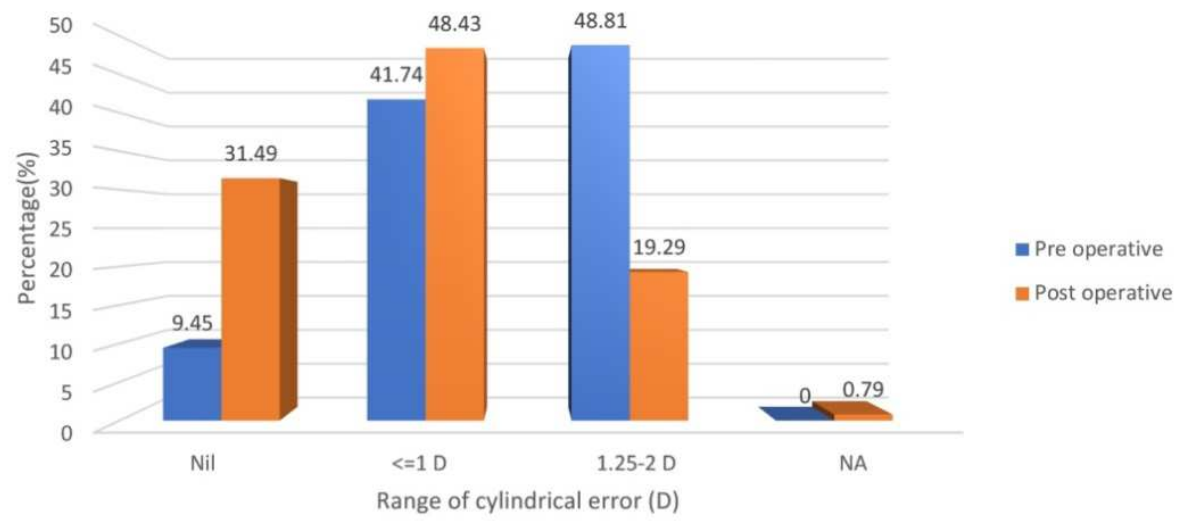

Figure 1. Comparison of pre operative and post operative astigmatism.

The post operative spherical refractive errors of the patients are elaborated in Table 3 . The mean post operative myopic spherical error was $-0.85+/-0.48$ D. $34.33 \%$ of the patients had a post operative refractive error out of which $87.42 \%$ had a myopic shift and $12.57 \%$ had a hypermetropic error $(<1 \mathrm{D})$.

Table 3. Post operative spherical error.

\begin{tabular}{lll}
\hline Error & Range & Number-\% \\
\hline & $0.25-0.75 \mathrm{D}$ & $96(18.9)$ \\
Myopia & $1-1.75 \mathrm{D}$ & $54(10.6)$ \\
& 2 D & $3(0.59)$ \\
& Mean myopic spherical error & $-0.85+/-0.48 \mathrm{D}$ \\
Hypermetropia & & $22(4.3)$ \\
Nil spherical error & & $333(65.56)$ \\
Total & & $508(100)$ \\
\hline
\end{tabular}

Among the 508 patients, $4.92 \%$ had complications like sub conjunctival haemorrhage, cystoid macular edema, graft retraction, episcleritis and recurrence of pterygia, out of which the most commonly seen complication was sub conjunctival haemorrhage followed by graft retraction (Table 4).

Table 4. Post operative complications.

\begin{tabular}{ll}
\hline Complication & Number \\
\hline SCH & 12 \\
CME & 2 \\
Graft retraction & 10 \\
Episcleritis & 1 \\
Recurrence & 5 \\
Nil & 480 \\
\hline
\end{tabular}

SCH-Sub Conjunctival Haemorrhage; CME-Cystoid Macular Edema

\section{Discussion}

With better surgical techniques and intraocular lens power calculation formulae, the refractive outcomes of cataract surgery have become precise and accurate. Simultaneous excision of pterygia along with cataract surgery, may have the potential to affect IOL power calculations, resulting in residual refractive errors in the post operative period.
However, a single step procedure of pterygium excision and cataract surgery is safe and has been found to have predictable visual outcomes [11]. This predictability of refractive outcomes depends on the size and grade of extension into cornea and pre operative keratometry values. A significant postoperative myopic shift may occur due to the steepening of the cornea after excision of the pterygium tissue, more so in large sized pterygia.

\subsection{Literature Review}

There have been studies which have shown that the effect of pterygia on keratometry values is significant enough to cause changes in the refraction [12-15]. Nejima et al [16] studied 562 eyes, and concluded that changes in topography after excision of pterygium were associated with the size of the pterygium. A significant association between the length of pterygium and the alteration in keratometric values post pterygium excision was also reported by Kim et al [17], with pterygia of less than $2 \mathrm{~mm}$ usually not affecting the keratometry significantly. Tomidokoro et al's [18] study revealed that excision of pterygia with a $20 \%$ extension onto the cornea will cause an increase of the corneal spherical power by $0.91 \mathrm{D}$, but they also concluded that this conclusion may be inaccurate.

The visual outcomes of simultaneous cataract with pterygium excision surgeries, have been studied only by a few $[8,9,11,19]$.

Ibechukwu et al [8] first showed the benefits of this combined surgical procedure as being cost effective and for providing better visual recovery to the patients. However, this study did not analyze the refractive changes following the surgery. In another study conducted by Gulani et al [9], 30 patients underwent combined cataract surgery with pterygium excision using bare sclera technique followed by beta radiation, out of which $63 \%$ of patients were found to have a post operative vision of $6 / 12$ with a mean with-therule astigmatism of $1.3 \mathrm{D}$ and against-the-rule astigmatism of $1.2 \mathrm{D}$ at the end of 6 months. Koc $\mathrm{M}$ et al [19] concluded in their study that any patient with a pterygium of more than $2.40 \mathrm{~mm}$ or $5.45 \mathrm{~mm}^{2}$ in size planned for a combined cataract 
surgery must have the IOL power under corrected by $0.5 \mathrm{D}$.

Kamiya et al [11] studied 60 eyes that underwent combined cataract with pterygium excision and reported that combined surgery was safe, effective with moderately predictable IOL power calculations. The refractive and visual outcomes in their study was comparable to the results of ours as elaborated in Table 5 .

Table 5. Comparison of results of our study with results of Kamiya et al [11].

\begin{tabular}{llll}
\hline Parameter & Our study & Kamiya et al \\
\hline Number of eyes studied & 508 & & 60 \\
Follow up period & 6 months & & 3 months \\
& Pre operative & Post operative & Pre operative \\
Mean BCVA (LogMAR) & $0.41+/-0.46$ & $0.04+/-0.1(\mathrm{p}<0.05)$ & $0.19+/-0.2 \quad$ Post operative \\
Mean manifest astigmatism (D) & $-1.25+/-0.60 \mathrm{D}$ & $-0.73+/-0.58 \mathrm{D}(\mathrm{p}<0.05)$ & $-1.43+/-1.21 \mathrm{D}$ \\
\hline
\end{tabular}

Our results show that combined phacoemulsification with pterygium excision resulted in no significant additional complications as compared to separate surgeries in two sittings. With regard to the visual outcomes, the combined procedure gave near predictable results and none of the patients had a cylindrical error of greater than 2 diopters. A myopic shift of less than $1 \mathrm{D}$ was noted in a significant number of patients which could be attributed to the steepening of the cornea following excision of the pterygium tissue.

An important point to note before proceeding for a combined procedure is to avoid any intra operative correction of pre operative cylindrical error. These may include relaxing incisions or the use of toric intraocular lenses (IOLs). This is due to the fact that the exact pre existing astigmatism cannot be distinguished from the astigmatism induced by the pterygia itself [20]. Thus, even in our study, only standard IOLs were placed in all cases.

\subsection{Strength of the Study}

This is a study of a large series of patients with a long term follow up with all cases being performed by a single surgeon and with uniform protocols and procedures followed for all patients leading to unbiased results.

\subsection{Limitations of the Study}

Comparing pre operative and post operative keratometric astigmatism would have been the ideal method of choice, but for practical purposes we have used the manifest astigmatism of the patients post operatively, as subjective cylindrical acceptance gives a better measure of visual outcome than corneal astigmatism alone.

Our results have shown $34.3 \%$ of the patients had a post operative spherical residual error and close to $63 \%$ of those with a myopic error had an error of lesser than $1 \mathrm{D}$. Accurate refractive results may not be possible while combining the two procedures due to subtle errors in IOL power calculation caused by the pterygia. This may be optimized by making the patients hyperopic by around $0.5 \mathrm{D}$ during IOL power calculations.

\subsection{What Was Known}

Combined surgery for co existing cataract with pterygium has been advocated infrequently due to the possibility of residual refractive errors and inaccuracy in pre operative intraocular lens power calculation. There have not been many studies involving a large population with long term follow up in patients who have undergone these combined procedures.

\subsection{What This Paper Adds}

This study involving a large case series with long term follow up has shown that simultaneous phacoemulsification with pterygium excision with conjunctival autografting produces minimal post operative spherical and cylindrical errors and that a meticulous pre operative case selection, patient counselling and evaluation is needed to optimize the visual outcomes in these patients.

\section{Conclusion}

This study shows that the combined single step procedure of phacoemulsification with pterygium excision in indicated cases, is found to be safe and effective with good visual outcomes. The post-operative myopic residual error can be anticipated and reduced by slightly under correcting the IOL power in patients with concurrent pterygium to optimize the visual outcome.

\section{References}

[1] J. C. S. Yam and A. K. H. Kwok et al, "Ultraviolet light and ocular diseases," International ophthalmology, vol. 34 , no. 2 , pp. 383-400, 2013.

[2] Kwok LS, Coroneo MT et al. A model for pterygium formation. Cornea 1994; 13: 219-24.

[3] Cameron $\mathrm{ME}$ et al: Pterygium throughout the world. Springfield, Charles C Thomas, 1965, pp 141-171.

[4] Hiller R, Giacometti L, Yuen K et al (1977) Sunlight and cataract: an epidemiologic investigation. Am J Epidemiol 105 (5): $450-459$.

[5] Hollows F, Moran D et al (1981) Cataract-The ultraviolet risk factor. Lancet 2 (8258): 1249-1250.

[6] Huchbaum DR, Moskowitz SE, Wirtschafter JD et al: A quantitative analysis of astigmatism induced by pterygium. J Biomech 10: 735746, 1977.

[7] Lim R, Mitchell P, Cumming RG et al. Cataract associations with pinguecula and pterygium: the Blue Mountains Eye Study. Am J Ophthalmol. 1998; 126: 717-719. 
[8] Ibechukwu BI et al. Simultaneous pterygium and intraocular surgery. Br J Ophthalmol. 1990; 74: 265-266.

[9] Gulani A, Dastur YK et al. Simultaneous pterygium and cataract surgery. J Postgrad Med. 1995; 41: 8-11.

[10] Kodavoor SK, Ramamurthy D, Tiwari NN, Ramamurthy S et al. Double-head pterygium excision with modified vertically split-conjunctival autograft: Six-year long-term retrospective analysis. Indian J Ophthalmol 2017; 65: 700-4.

[11] Kamiya, Kazutaka MD, PhD; Shimizu, Kimiya MD, PhD et al. Predictability of Intraocular Lens Power Calculation After Simultaneous Pterygium Excision and Cataract Surgery. Medicine, December 2015 - Volume 94 - Issue 52 - p e2232.

[12] Cinal A, Yasar T, Demirok A, et al. The effect of pterygium surgery on corneal topography. Ophthalmic Surg Lasers. 2001; 32: 35-40.

[13] Yasar T, Ozdemir M, Cinal A, et al. Effects of fibrovascular traction and pooling of tears on corneal topographic changes induced by pterygium. Eye (Lond). 2003; 17: 492-496.

[14] Errais K, Bouden J, Mili-Boussen I, et al. Effect of pterygium surgery on corneal topography. Eur J Ophthalmol. 2008; 18: 177-181.
[15] Wu PL, Kuo CN, Hsu HL, et al. Effect of pterygium surgery on refractive spherocylinder power and corneal topography. Ophthalmic Surg Lasers Imaging. 2009; 40: 32-37.

[16] Nejima R, Masuda A, Minami K, et al. Topographic changes after excision surgery of primary pterygia and the effect of pterygium size on topograpic restoration. Eye Contact Lens. 2015; 41: 58-63.

[17] Kim SW, Park S, Im CY, et al. Prediction of mean corneal power change after pterygium excision. Cornea. 2014; 33: $148-153$.

[18] Tomidokoro A, Miyata K, Sakaguchi Y, et al. Effects of pterygium on corneal spherical power and astigmatism. Ophthalmology. 2000; 107: 1568-1571.

[19] Koc M, Uzel MM et al, Pterygium size and effect on intraocular lens power calculation. J Cataract Refract Surg. 2016 Nov; 42 (11): 1620-1625.

[20] Gumus, Koray \& I. Tung, Cynthia \& Al-Mohtaseb, Zaina et al (2017). Management of Pterygium with Coexisting Cataract. 10.5005/jp/books/13069_21. 